\title{
Dysfunction of calcium/calmodulin/CaM kinase II $\alpha$ cascades in the medial prefrontal cortex in post-traumatic stress disorder
}

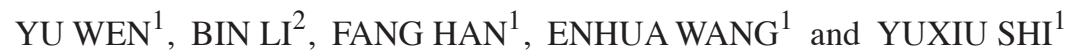 \\ ${ }^{1}$ Department of Histology and Embryology, Institute of Pathology and Pathophysiology, Basic Medical Sciences College; \\ ${ }^{2}$ Department of Orthopaedic Surgery, Shengjing Hospital, China Medical University, Shenyang, Liaoning 110001, P.R. China
}

Received February 28, 2012; Accepted July 25, 2012

DOI: $10.3892 / \mathrm{mmr} .2012 .1022$

\begin{abstract}
Post-traumatic stress disorder (PTSD) is a significant problem that may affect individuals who have been exposed to a traumatic event or events, including combat, violent crime or childhood abuse. The medial prefrontal cortex (mPFC) is known to be significantly involved in emotional adjustment, particularly introspection, amygdala inhibition and emotional memory. In the acute phase of severe traumatic stress, the mPFC appears to undergo a change in plasticity for a short time, which suggests that the mPFC may be the reponse-sensitizing region. Calcium $\left(\mathrm{Ca}^{2+}\right)$ is one of most significant intracellular messengers; the appropriate concentration of $\mathrm{Ca}^{2+}$ is necessary for neuronal excitability. When the $\mathrm{Ca}^{2+}$ concentration increases, $\mathrm{Ca}^{2+}$, calmodulin $(\mathrm{CaM})$ and $\mathrm{CaM}$ kinase II $\alpha$ (CaMKII $\alpha$ ) combine together to form the $\mathrm{Ca}^{2+}-\mathrm{CaM}-\mathrm{CaMKII} \alpha$ signaling pathway, which is important in the plasticity of the central nervous system, learning and memory, mind, behavior and other types of cognitive activities. Our team studied the changes in the $\mathrm{Ca}^{2+}-\mathrm{CaM}-\mathrm{CaMKII} \alpha$ levels in the $\mathrm{mPFC}$ of rats following a single-prolonged stress (SPS). The SPS, a credible method for establishing a rat model of PTSD, has been internationally recognized. The free intracellular $\mathrm{Ca}^{2+}$ concentration in the mPFC in the PTSD group was significantly higher than that in the control group 1 day after SPS exposure $(\mathrm{P}<0.05)$ and decreased 7 days after SPS; $\mathrm{CaM}$ expression significantly increased, while CaMKII $\alpha$ expression significantly decreased in the mPFC 1 day after SPS compared with the control group. These findings suggest dysfunction of the $\mathrm{Ca}^{2+}-\mathrm{CaM}-\mathrm{CaMKII} \alpha$ cascades in the mPFC, which may relate to the pathogenesis of the abnormal functioning of the mPFC in PTSD.
\end{abstract}

Correspondence to: Professor Yuxiu Shi, Department of Histology and Embryology, Institute of Pathology and Pathophysiology, Basic Medical Sciences College, China Medical University, 92 Beier Road, Heping, Shenyang, Liaoning 110001, P.R. China

E-mail: wylb7475@163.com

Key words: single-prolonged stress, post-traumatic stress disorder, calcium, calmodulin, CaM kinase II $\alpha$, medial prefrontal cortex

\section{Introduction}

Post-traumatic stress disorder (PTSD) is an anxiety disorder that may develop following exposure to the threat of death or serious injury and may cause affected invididuals to continuously re-experience the traumatic event $(1,2)$ and react with intense fear, helplessness or horror for years. Patients with this disorder persistently re-experience their traumatic events in various ways, including intrusive and disturbing recollections, nightmares, flashbacks and distress and physiological reactivity on exposure to reminders of the event (3). These individuals often avoid reminders of the traumatic event and experience a restricted range of effects.

One of the core neuroendocrine abnormalities related to PTSD is the dysfunction of the hypothalamic-pituitary-adrenal (HPA) axis, characterized by low levels of adrenocorticotropic hormone (ACTH), plasma cortisol and urinary cortisol and enhanced suppression of cortisol in response to low-dose dexamethasone administration $(4,5)$. These neuroendocrine findings specific to PTSD have served as the basis for animal models and are useful for elucidating the pathophysiology of PTSD. Single-prolonged stress (SPS) is a reliable animal model of PTSD based on the time-dependent dysregulation of the HPA axis which has been developed and employed for PTSD studies $(6,7)$. SPS has been shown to induce enhanced inhibition of the HPA axis, which is a putative neuroendocrinological hallmark of PTSD (8). In addition, SPS rats also exhibit behavioral abnormalities (enhanced anxiety) that mimic the symptoms of PTSD. SPS paradigms have been extensively applied in the investigation of PTSD (9).

A convergent body of human and non-human studies suggests that the amygdala mediates the acquisition and expression of conditioned fear and the enhancement of emotional memory (10), whereas the medial prefrontal cortex (mPFC) mediates the extinction of conditioned fear and the volitional regulation of negative emotion (11). It has been theorized that the mPFC exerts an inhibitory effect on the amygdala and that a defect in this inhibition could account for the symptoms of PTSD (12). A study of brain-injured and trauma-exposed combat veterans confirmed that amygdala damage reduces the likelihood of developing PTSD (13). However, contrary to the prediction of the top-down inhibition model, mPFC damage also reduces the likelihood of 
developing PTSD. The mPFC contributes significantly to the modulation of memory consolidation with the storage of emotionally relevant information and is critical for the formation of long-term aversive memory, particularly for the modulation of anxiety, fear and aggression (14). In addition, the $\mathrm{mPFC}$ may inhibit the effect of the amygdala following SPS in PTSD rats and may also be related to impaired fear extinction. It has been confirmed by computed tomography and functional magnetic resonance imaging that the mPFC of patients with PTSD are notably smaller than normal.

Calcium $\left(\mathrm{Ca}^{2+}\right)$ is an influential intracellular secondary messenger. Elevated $\mathrm{Ca}^{2+}$ binds to numerous proteins, including low-affinity/high-capacity buffer proteins. The influx of $\mathrm{Ca}^{2+}$ ions results in calmodulin (CaM) activation. A number of $\mathrm{Ca}^{2+} / \mathrm{CaM}$ targets modulate cellular signaling pathways. CaM kinase II (CaMKII) is a major mediator of calcium signaling and is of particular importance in the brain, contributing significantly to the regulation of nerve functions $(15,16)$.

In this study, our team briefly examined the changes in $\mathrm{Ca}^{2+}-\mathrm{CaM}-\mathrm{CaMKII} \alpha$ levels in the mPFC in order to ascertain how $\mathrm{Ca}^{2+}-\mathrm{CaM}-\mathrm{CaMKII} \alpha$ cascades participate in PTSD.

\section{Materials and methods}

Animal model preparation and grouping. A total of 21 male Wistar rats were randomly divided into a control and SPS groups of 1 (1-day) and 7 days (7-day). The control rats remained in their home cages with no handling for 7 days and were sacrificed at the same time as the SPS groups. The SPS rats underwent the SPS procedure on the first day. The SPS protocol $(7,9)$ consisted of: a 2 -h immobilization (compression with plastic bags), a 20 -min forced swim $\left(25^{\circ} \mathrm{C}\right)$, and a 15 -min rest, followed by ether anesthesia (until loss of consciousness). Following SPS, the rats were fed routinely. The study was approved by the ethics committee of China Medical University.

Intracellular free calcium in $\mathrm{mPFC}$ cells. Rats of the control and SPS groups were decapitated rapidly and the brains were removed and immediately placed in a dish standing on crushed ice. The mPFC was then dissected out according to the atlas of rats (17), snap-frozen in liquid nitrogen and prepared for cell suspension using a routine method. Furthermore, the cell suspension was loaded with $1 \mathrm{mmol} / 1$ fura-2-acetoxymethyl ester (Fura-2/AM) (Beyotime Institute of Biotechnology, Haimen, China) for $35 \mathrm{~min}$ and then detected with a spectrofluorometer.

Immunohistochemistry. Rats of the control and SPS groups were prepared by left ventricle perfusion fixation (18) with $4 \%$ buffered paraformaldehyde and the mPFCs were post-fixed in the same fixative at $4^{\circ} \mathrm{C}$ for $24 \mathrm{~h}$ and then embedded in paraffin. Paraffin sections $(5-\mu \mathrm{m})$ were prepared for the morphological studies. The mPFC sections were treated with $5 \%$ bovine serum albumin (BSA) and $0.3 \%$ Triton X-100 in PBS for $30 \mathrm{~min}$ at room temperature for blocking of non-specific staining, followed by incubation with mouse monoclonal antibody against CaM (Sigma, St. Louis, MO, USA; 1:100) or CaMKII $\alpha$ (Santa Cruz Biotechnology, Inc., Santa Cruz, CA, USA; 1:200) overnight at $4^{\circ} \mathrm{C}$. Following incubation with goat anti-mouse IgG (Boster, Wuhan, China; 1:100) for $2 \mathrm{~h}$, sections were treated with the streptomycin-avidin-biotinperoxidase complex (SABC) for $1 \mathrm{~h}$ at room temperature. Moreover, they were washed three times with PBS following each incubation and subsequently incubated with 3,3'-diaminobenzidine (DAB) and $\mathrm{H}_{2} \mathrm{O}_{2}$. In order to assess non-specific staining, a few sections in every experiment were processed with the omission of the antibody.

Western blotting. Fresh mPFC of the control and SPS rats were respectively homogenized with sample buffer containing $200 \mathrm{mM}$ TBS, pH 7.5, 4\% sodium dodecyl sulfate (SDS), 20\% glycerol and 10\% 2-mercaptoethanol and were denatured by boiling for $3 \mathrm{~min}$. The protein fraction $(30 \mu \mathrm{g} /$ lane) extracted from each sample was separated by $12 \%(\mathrm{w} / \mathrm{v})$ gradient SDS-polyacrylamide gel electrophoresis (PAGE) and transferred to a PVDF membrane (Millipore, Bedford, MA, USA). After blocking with 5\% dried skimmed milk in $0.05 \%$ Tween-20-containing TBST at room temperature for $2 \mathrm{~h}$ and incubating with a primary antibody comprising a mouse monoclonal antibody against $\mathrm{CaM}(1: 1,000)$ or CaMKII $\alpha(1: 5,000)$ overnight at $4^{\circ} \mathrm{C}$, respectively, the membrane was incubated with anti-mouse IgG-HRP (Santa Cruz Biotechnology, Inc.; 1:5000) secondary antibodies for another $2 \mathrm{~h}$ at room temperature. Finally, the PVDF membrane was washed three times with TBST prior to visualization using enhanced chemiluminescence (ECL; Amersham Pharmacia Biotech, Buckinghamshire, UK).

Reverse transcription-polymerase chain reaction. The total mRNA from the mPFC was extracted using the TRIzol kit according to the manufacturer's instructions. The forward and reverse sequences of the primers (synthesized by Shenggong Biotech Co., Shanghai, China) were according to the serial numbers from GenBank and are listed in Table I (19). The cycling reaction for CaM was as follows: $94^{\circ} \mathrm{C}$ for $4 \mathrm{~min}$, followed by amplification for 32 cycles of $30 \mathrm{sec}$ at $94^{\circ} \mathrm{C}, 30 \mathrm{sec}$ at $58^{\circ} \mathrm{C}$ and $40 \mathrm{sec}$ at $72^{\circ} \mathrm{C}$ and a final $7-\mathrm{min}$ extension at $72^{\circ} \mathrm{C}$. For CaMKII $\alpha$, the reaction was started at $95^{\circ} \mathrm{C}$ for $2 \mathrm{~min}$, followed by amplification for 33 cycles of $30 \mathrm{sec}$ at $95^{\circ} \mathrm{C}, 30 \mathrm{sec}$ at $55^{\circ} \mathrm{C}$ and $40 \mathrm{sec}$ at $72^{\circ} \mathrm{C}$ and a final 5-min extension at $95^{\circ} \mathrm{C}$. $\beta$-actin mRNA used as an internal control was co-amplified with $\mathrm{CaM}$ and CaMKII $\alpha$. The products were observed following electrophoresis on a $1.2 \%$ agarose gel and the density of each band was analyzed on the Gel Image Analysis System. The levels of CaM and CaMKII $\alpha$ mRNA were determined by calculating the density ratios of $\mathrm{CaM}$ mRNA/ $\beta$-actin mRNA and $\mathrm{CaMKII} \alpha$ mRNA/ $\beta$-actin mRNA.

Statistical analysis. All data were expressed as the mean \pm standard deviation (SD). Data analysis among groups was performed using one-way analysis of variance (ANOVA) with SPSS 13.0 software. $\mathrm{P}<0.05$ was considered to indicate a statistically significant difference.

\section{Results}

Free $\mathrm{Ca}^{2+}$ concentration in $M P F C$. The intracellular free $\mathrm{Ca}^{2+}$ levels in the mPFC neurons were notably higher than in the 
Table I. Primer sequences for CaM and CaMKII $\alpha$.

\begin{tabular}{|c|c|c|c|}
\hline Name & $\begin{array}{l}\text { Upstream primer } \\
\qquad\left(5^{\prime}-3^{\prime}\right)\end{array}$ & $\begin{array}{l}\text { Downstream primer } \\
\qquad\left(5^{\prime}-3^{\prime}\right)\end{array}$ & $\begin{array}{c}\text { Product size } \\
\text { (bp) }\end{array}$ \\
\hline $\mathrm{CaM}$ & ggcatcctgctt tagcctgag & acatgctatcce tctcgtgtga & 328 \\
\hline CaMKII $\alpha$ & catcctcaccactatgctg & atcgatgaaagtccaggccg & 284 \\
\hline$\beta$-actin & atcacccacactgtgcccatc & acagagtacttgcgctcagga & 542 \\
\hline
\end{tabular}

CaM, calmodulin; CaMKII $\alpha$, CaM kinase II $\alpha$.

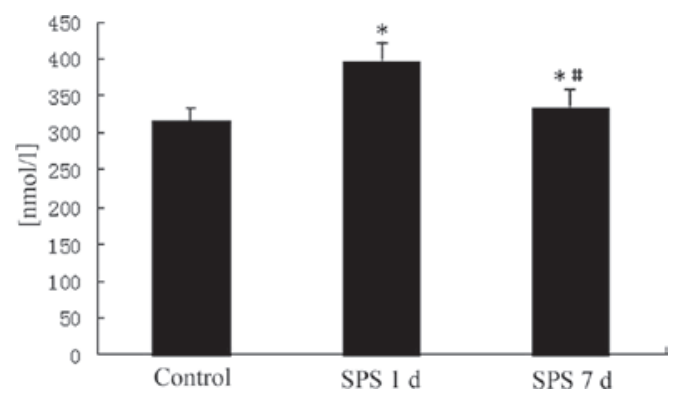

Figure 1. Changes of intracellular calcium $\left(\mathrm{Ca}^{2+}\right)$ levels (nmol/l) (mean $\left.\pm \mathrm{SD}\right)$. ${ }^{*} \mathrm{P}<0.05$ vs. the control group, ${ }^{\#} \mathrm{P}<0.05$ vs. the single-prolonged stress (SPS) 1-day group.

control group 1 day after SPS and had returned to normal levels 7 days after SPS (Fig. 1).

Immunohistochemical observation of CaM and CaMKIIL. Our team observed the CaM and CaMKII $\alpha$ levels in the mPFC of the control and SPS rats. The sites of expression of $\mathrm{CaM}$ and CaMKII $\alpha$ were distributed mainly in the cytoplasm and appeared as buffy particles (Fig. 2A and D). In SPS rats, increased $\mathrm{CaM}$ levels were observed; the highest expression levels were identified 1 day after SPS stimulation (Fig. 2B and $\mathrm{C}$ ); by contrast, decreased CaMKII $\alpha$ levels were observed (Fig. 2E and F).

Western blotting of CaM and CaMKII $\alpha$. The CaM, CaMKII $\alpha$ and $\beta$-actin immunoreactive signals appeared at 16.7, 50 and $42 \mathrm{kDa}$, respectively (data not shown), and the band density mean value of the control group was set as $100 \%$. Data were expressed as normalized optical density.

In the SPS group, the expression of CaM protein in the mPFC was highest on day 1 and was downregulated a little on day 7 , but remained higher than the control. Significantly lower protein expression of CaMKII $\alpha$ was identified in the SPS group compared with the control on days 1 and 7 (Fig. 3).

$m R N A$ expression of CaM and CaMKII $\alpha$. The mRNA levels of $\mathrm{CaM}$ and $\mathrm{CaMKII} \alpha$ were normalized to the $\beta$-actin mRNA level. The mRNA expression levels of CaM significantly increased in the mPFC of the SPS group compared
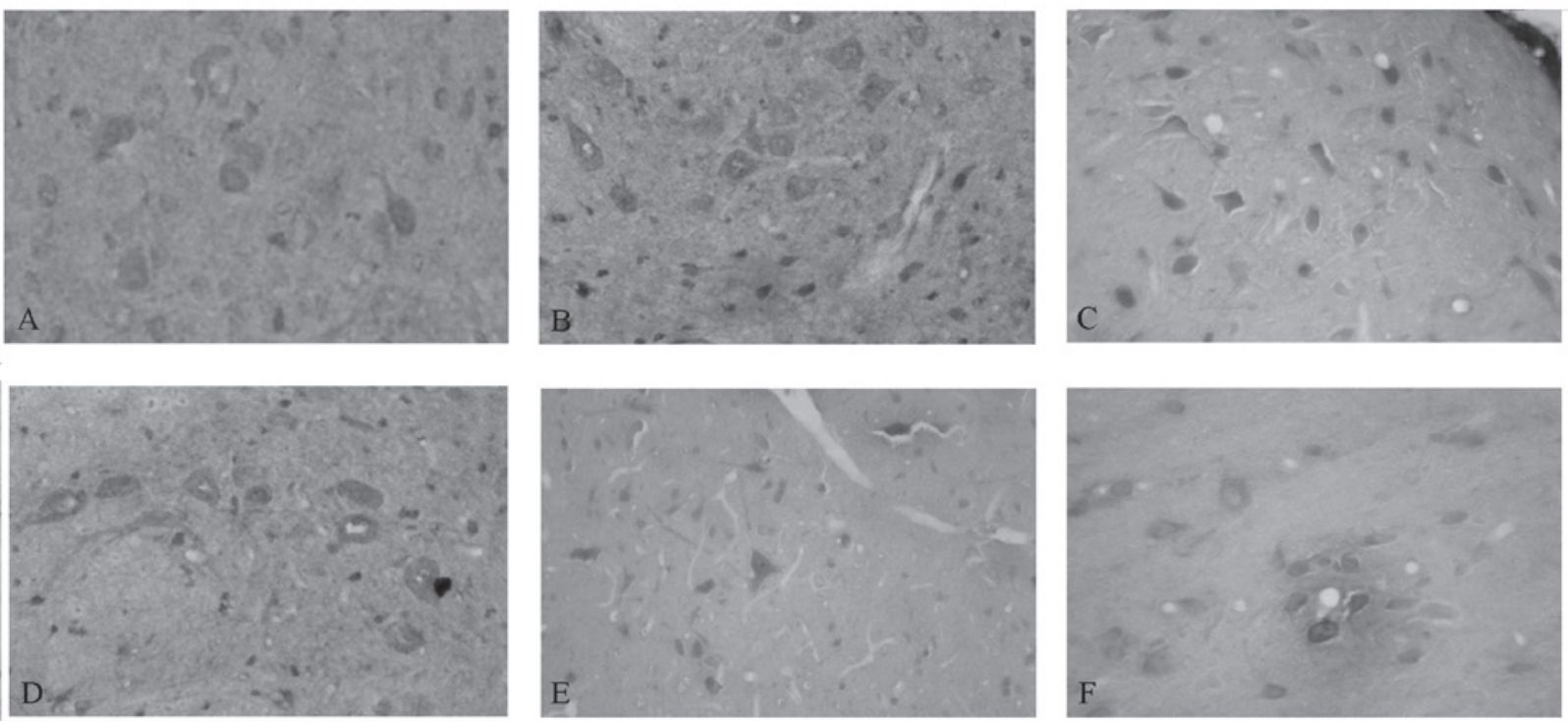

Figure 2. Expression of calmodulin (CaM) and CaM kinase II $\alpha(\mathrm{CaMKII} \alpha)$ in the medial prefrontal cortex (mPFC) in each group (A-F, magnification x400). The quantity of CaM-immunoreactive cells in (B) the 1-day single-prolonged stress (SPS) rats exceeds that of (A) the control and (C) 7-day SPS rats. The quantity of CaMKII $\alpha$-immunoreactive cells in (E) the 1-day SPS rats was less than that in (D) the control and (F) 7-day SPS rats. 
A

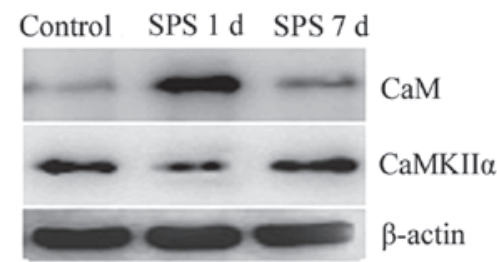

B

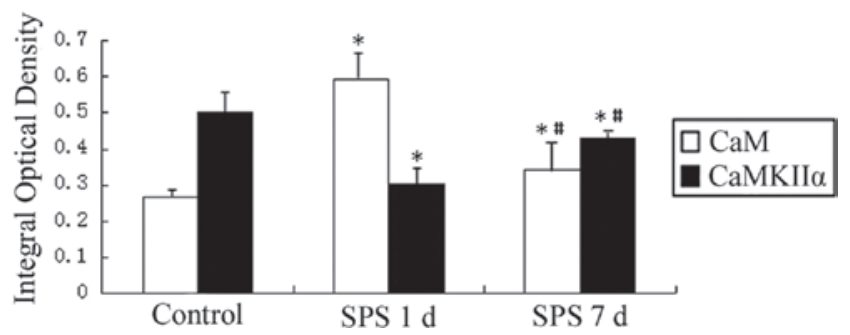

Figure 3. (A) Protein expression levels and (B) quantitative analysis result of calmodulin $(\mathrm{CaM})$ and $\mathrm{CaM}$ kinase II $\alpha(\mathrm{CaMKII} \alpha)$ in the medial prefrontal cortex (mPFC) of the control and single-prolonged stress (SPS) rats by western blotting. Increased $\mathrm{CaM}$ and decreased CaMKII $\alpha$ expression levels were observed in the SPS rats compared with the control. ${ }^{*} \mathrm{P}<0.05$ vs. the control group, ${ }^{\#} \mathrm{P}<0.05$ vs. the 1 -day SPS group
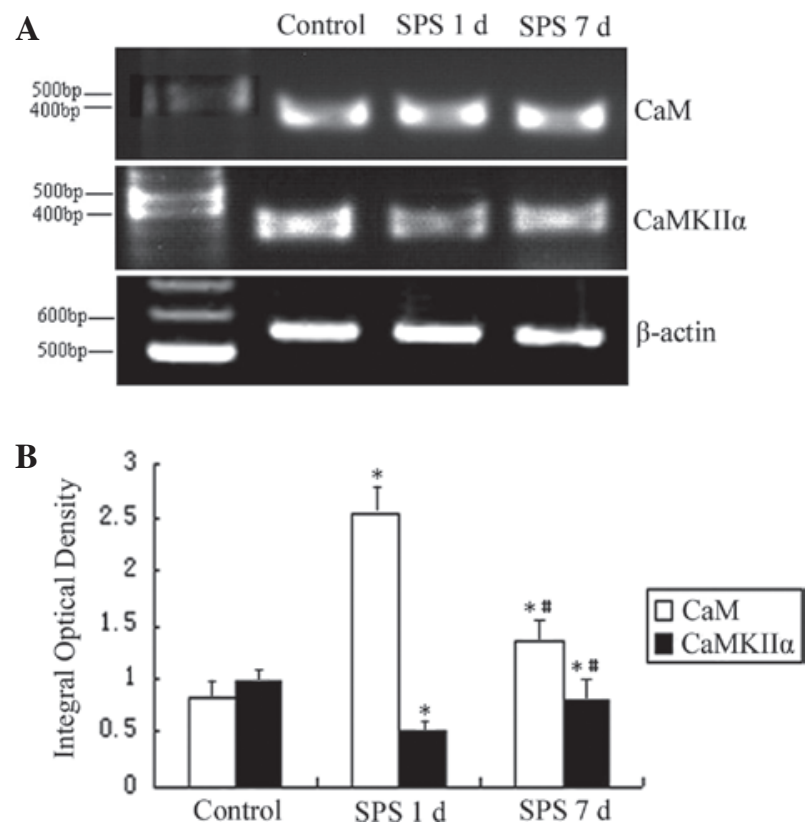

Figure 4. (A) Expression levels of and (B) quantitative analysis results for the mRNA of calmodulin $(\mathrm{CaM})$ and $\mathrm{CaM}$ kinase II $\alpha(\mathrm{CaMKII} \alpha)$ in the medial prefrontal cortex (mPFC) in control and single-prolonged stress (SPS) rats. Increased $\mathrm{CaM}$ and decreased $\mathrm{CaMKII} \alpha$ expression levels were observed in the SPS rats compared with the control. ${ }^{*} \mathrm{P}<0.05$ vs. the control group, ${ }^{\#} \mathrm{P}<0.05$ vs. the 1 -day SPS group.

with the control rats. However, the mRNA expression levels of CaMKII $\alpha$ markedly decreased in the SPS group rats (Fig. 4).

\section{Discussion}

Over the past decade, basic animal research and human neuroimaging studies have begun to outline the specific neural circuitry dedicated to emotional functioning (20). These studies have partially inspired hypotheses with regard to the dysfunction in this circuitry that leads to the development and maintenance of PTSD. While they have provided useful initial information and guided the initial functional neuroanatomical and neurophysiological studies into PTSD, it is becoming increasingly clear that the scope of these studies does not fully capture the complexity of the changes occurring during trauma exposure and PTSD development.

Evidence that the mPFC is involved in a neural mechanism that modulates a differential susceptibility of multiple memory systems to emotional arousal during acquisition, memory consolidation (21) and/or memory retrieval, may provide a novel approach to elucidating the range of mnemonic dysfunctions in PTSD.

The mPFC is significantly involved in emotional adjustment. The function of emotional adjustment was induced in PTSD. With the extension of the SPS stimulation time, an increasing number of neurons of the mPFC of rats became smaller (22) and the outline of the small neurons was indistinct. In the future, this finding may help scientists to understand how brain damage is likely to affect thought, action and the ability to reflect.

The volitional control of negative emotion is another affective function that is germane to PTSD and one in which the $\mathrm{mPFC}$ and amygdala again are significant (23). That is, during emotional regulation, an increase in the activity of the mPFC is associated with a decrease in the activity of the amygdala as well as with the experience of negative effects. Furthermore, this normative mPFC-amygdala inverse coupling during emotional regulation is disrupted in patients with major depressive disorder, which is characterized by pathologically high levels of negative effects.

The special role of the $\mathrm{mPFC}$ in the processing of threat-related stimuli, particularly anger and fear, is well documented (24). Abundant evidence from animal and human investigations strongly suggests that the $\mathrm{mPFC}$ is responsible for the enhancement of explicit memory associated with emotional arousal $(25,26)$. In addition, numerous lines of evidence have implicated the mPFC as a substrate for the stress-related modulation of memory.

$\mathrm{CaM}$, as a ubiquitous $\mathrm{Ca}^{2+}$ sensor protein, is involved in almost all intracellular events. CaMKII $\alpha$ is the molecular basis of learning and memory (27), but in the absence of bound $\mathrm{Ca}^{2+} / \mathrm{CAM}, \mathrm{CaMKII}$ is in an inactive conformation. The influx of $\mathrm{Ca}^{2+}$ results in CaMKII activation. $\mathrm{Ca}^{2+} / \mathrm{CaMKII}$ is a major mediator of $\mathrm{Ca}^{2+}$ signaling and is of particular importance in the brain, contributing significantly to the regulation of nerve functions, including learning and memory (28). It is speculated that CaMKII $\alpha$ responds to a strong and/or repeated stimulus in which the cellular $\mathrm{Ca}^{2+}$ concentration is relatively high. CaMKII $\alpha$ is highly effective in synaptic plasticity and is considered as one of the best candidates for a memory molecule (29).

In this study, the detection of free $\mathrm{Ca}^{2+}$ in the mPFC neurons revealed $\mathrm{Ca}^{2+}$ overload 1 day after SPS stimulation. Further analysis of $\mathrm{CaM}$, the main $\mathrm{Ca}^{2+}$-conjugated protein in the CNS, revealed that the expression of total $\mathrm{CaM}$ in the mPFC markedly increased 1 day after SPS stimulation, suggesting that the CaM content changed synchronously with changes in the $\mathrm{Ca}^{2+}$ concentration. This occurred as a result of the SPS increasing the intracellular free $\mathrm{Ca}^{2+}$ levels in the mPFC neurons and thereby inducing the overexpression of CaM. The change in 
CaMKII $\alpha$ from inactive to active led to a decreased content of CaMKII $\alpha$ in the mPFC following SPS exposure. Due to the importance of the $\mathrm{Ca}^{2+}-\mathrm{CaM}-\mathrm{CaMKII} \alpha$ signaling pathway in the plasticity of the central nervous system, learning and memory, mind, behavior and other types of cognitive activities (30), the dysfunction of the $\mathrm{Ca}^{2+}-\mathrm{CaM}-\mathrm{CaMKII} \alpha$ pathway of the mPFC might be the pathobiological basis for the abnormality of affect and behavior induced by PTSD.

To date, the pathogenesis of PTSD has not been entirely clarified. PTSD may result in a series of biochemical and physiological abnormalities in the brain, which lead to dysfunction of the mPFC. Thus, the pathogenesis of PTSD requires further study.

In conclusion, the SPS rats exhibit behavioral abnormalities that mimic the symptoms of PTSD. The dysfunction of $\mathrm{Ca}^{2+}-\mathrm{CaM}-\mathrm{CaMKII} \alpha$ in the SPS rats decreases the inhibition of the amygdala, which might be the pathobiological basis of the abnormality of affect and behavior induced by PTSD.

\section{Acknowledgements}

The authors would like to thank all staff members of the China Medical University Experiment Center for their technical support. In addition, this study was supported by a grant from the National Natural Science Foundation of China (no. 81171282).

\section{References}

1. Liberzon I and Martis B: Neuroimaging studies of emotional responses in PTSD. Ann NY Acad Sci 1071: 87-109, 2006.

2. Shin LM, Wright CI, Cannistraro PA, Wedig MM, McMullin K, Martis B, Macklin ML, Lasko NB, Cavanagh SR, Krangel TS, et al: A functional magnetic resonance imaging study of amygdala and medial prefrontal cortex responses to overtly presented fearful faces in posttraumatic stress disorder. Arch Gen Psychiatry 62: 273-281, 2005.

3. Liberzon I, King AP, Britton JC, Phan KL, Abelson JL and Taylor SF: Paralimbic and medial prefrontal cortical involvement in neuroendocrine responses to traumatic stimuli. Am J Psychiatry 164: 1250-1258, 2007.

4. Eckart C, Stoppel C, Kaufmann J, Tempelmann C, Hinrichs H, Elbert T, Heinze HJ and Kolassa IT: Structural alterations in lateral prefrontal, parietal and posterior midline regions of men with chronic posttraumatic stress disorder. J Psychiatry Neurosci 36: 176-186, 2011.

5. Shin LM, Rauch SL and Pitman RK: Amygdala, medial prefrontal cortex, and hippocampal function in PTSD. Ann NY Acad Sci 1071: 67-79, 2006.

6. Hughes KC and Shin LM: Functional neuroimaging studies of post-traumatic stress disorder. Expert Rev Neurother 11: 275-285, 2011.

7. Koenigs M and Grafman J: Posttraumatic stress disorder: the role of medial prefrontal cortex and amygdala. Neuroscientist 15: $540-548,2009$.

8. Adou E, Miller JS, Ratovoson F, Birkinshaw C, Andriantsiferana R, Rasamison VE and Kingston DG: Antiproliferative cardenolides from Pentopetia androsaemifolia Decne. from the Madagascar rain forest. Indian J Exp Biol 48: 248-257, 2010.

9. Weinberg MS, Johnson DC, Bhatt AP and Spencer RL: Medial prefrontal cortex activity can disrupt the expression of stress response habituation. Neuroscience 168: 744-756, 2010.

10. Chang CH, Berke JD and Maren S: Single-unit activity in the medial prefrontal cortex during immediate and delayed extinction of fear in rats. PLoS One 5: e11971, 2010.
11. St Jacques PL, Botzung A, Miles A and Rubin DC: Functional neuroimaging of emotionally intense autobiographical memories in post-traumatic stress disorder. J Psychiatr Res 45: 630-637, 2011.

12. King AP, Abelson JL, Britton JC, Phan KL, Taylor SF and Liberzon I: Medial prefrontal cortex and right insula activity predict plasma ACTH response to trauma recall. Neuroimage 47: 872-880, 2009

13. Shaw ME, Moores KA, Clark RC, McFarlane AC, Strother SC, Bryant RA, Brown GC and Taylor JD: Functional connectivity reveals inefficient working memory systems in post-traumatic stress disorder. Psychiatry Res 172: 235-241, 2009.

14. Sailer U, Robinson S, Fischmeister FP, König D, Oppenauer C, Lueger-Schuster B, Moser E, Kryspin-Exner I and Bauer H: Altered reward processing in the nucleus accumbens and medial prefrontal cortex of patients with posttraumatic stress disorder. Neuropsychologia 46: 2836-2844, 2008.

15. Geuze E, Westenberg HG, Heinecke A, de Kloet CS, Goebel R and Vermetten E: Thinner prefrontal cortex in veterans with posttraumatic stress disorder. Neuroimage 41: 675-681, 2008.

16. Bremner JD, Elzinga B, Schmahl C and Vermetten E: Structural and functional plasticity of the human brain in posttraumatic stress disorder. Prog Brain Res 167: 171-186, 2008.

17. Paxinos G and Watson C (eds): The Rat Brain in Stereotaxic Coordinates. 4th edition. Academic Press, San Diego, CA, 1998.

18. Liberzon I and Sripada CS: The functional neuroanatomy of PTSD: a critical review. Prog Brain Res 167: 151-169, 2008.

19. Xiao B, Han F and Shi YX: Dysfunction of $\mathrm{Ca}^{2+} / \mathrm{CaM}$ kinase IIalpha cascades in the amygdala in post-traumatic stress disorder. Int J Mol Med 24: 795-799, 2009.

20. Williams LM, Kemp AH, Felmingham K, Barton M, Olivieri G, Peduto A, Gordon E and Bryant RA: Trauma modulates amygdala and medial prefrontal responses to consciously attended fear. Neuroimage 29: 347-357, 2006.

21. Hull AM: Neuroimaging findings in post-traumatic stress disorder. Systematic review. Br J Psychiatry 181: 102-110, 2002.

22. Rauch SL, Shin LM and Phelps EA: Neurocircuitry models of posttraumatic stress disorder and extinction: human neuroimaging research-past, present, and future. Biol Psychiatry 60: 376-382, 2006.

23. Corbo V, Clément MH, Armony JL, Pruessner JC and Brunet A: Size versus shape differences: contrasting voxel-based and volumetric analyses of the anterior cingulate cortex in individuals with acute posttraumatic stress disorder. Biol Psychiatry 58: $119-124,2005$.

24. Anderson MC and Green C: Suppressing unwanted memories by executive control. Nature 410: 366-369, 2001.

25. Cabeza R, Ciaramelli E, Olson IR and Moscovitch M: The parietal cortex and episodic memory: an attentional account. Nat Rev Neurosci 9: 613-625, 2008.

26. Cardinal RN, Parkinson JA, Hall J and Everitt BJ: Emotion and motivation: the role of the amygdala, ventral striatum, and prefrontal cortex. Neurosci Biobehav Rev 26: 321-352, 2002.

27. Muigg P, Hetzenauer A, Hauer G, Hauschild M, Gaburro S, Frank E, Landgraf R and Singewald N: Impaired extinction of learned fear in rats selectively bred for high anxiety-evidence of altered neuronal processing in prefrontal-amygdala pathways. Eur J Neurosci 28: 2299-2309, 2008.

28. Milad MR, Pitman RK, Ellis CB, Gold AL, Shin LM, Lasko NB, Zeidan MA, Handwerger K, Orr SP and Rauch SL: Neurobiological basis of failure to recall extinction memory in posttraumatic stress disorder. Biol Psychiatry 66: 1075-1082, 2009.

29. Akirav I and Maroun M: The role of the medial prefrontal cortex-amygdala circuit in stress effects on the extinction of fear. Neural Plast 2007: 30873, 2007.

30. Milad MR, Vidal-Gonzalez I and Quirk GJ: Electrical stimulation of medial prefrontal cortex reduces conditioned fear in a temporally specific manner. Behav Neurosci 118: 389-394, 2004. 